\title{
Knowledge, attitudes and use of labour analgesia among women at a low-income country antenatal clinic
}

\author{
Mary T. Nabukenya ${ }^{1 *}$, Andrew Kintu', Agnes Wabule1, Mark T Muyingo² and Arthur Kwizera'
}

\begin{abstract}
Background: Childbirth is one of the most painful experiences of a woman's life. Authorities in the fields of obstetrics and anaesthesia encourage use of labour analgesia. Unlike in high-income countries, pain relief in labour in Africa is not a well established service, especially in the low-income countries like Uganda. Little is known about whether parturients would be amenable to labour analgesia. We sought to determine knowledge, attitudes and use of labour analgesia among women attending the antenatal clinic at Mulago National Referral Hospital.

Methods: Upon obtaining institutional approval, we conducted a cross-sectional descriptive study. Women were requested to complete the researcher-administered survey following informed consent. The study was conducted in the general antenatal clinic at the Mulago National Referral Hospital.

Results: Of 1293 participants interviewed, only $7 \%$ of the participants had knowledge of labour analgesia. Of the multiparous mothers $87.9 \%$ did not have labour analgesia in their previous deliveries, although $79.2 \%$ of them had delivered in a national referral hospital. The commonest reason for refusal of labour analgesia was to experience natural childbirth. $87.7 \%$ of the participants wanted labour analgesia for their next delivery.
\end{abstract}

Conclusion: There is a wide gap between the desire for labour analgesia and its availability. Obstetricians and anaesthesiologists have a role to educate the women, and to provide this much desired service.

Keywords: Labour Analgesia, Perceptions, Low-and-middle income country, Uganda

\section{Background}

The pain of childbirth has been documented to be extreme. A lot of controversy has existed since the inception of pain relief in labour to date. According to the American Society of Anesthesiologists (ASA) and American College of Obstetricians and Gynecologists (ACOG), maternal request represents sufficient justification for pain relief $[1,2]$. The American College of Obstetricians and Gynecologists also states that 'labour results in severe pain for many women. There is no other circumstance where it is considered acceptable for a person to experience untreated severe pain, amenable to safe intervention, while under a physician's care' [3].

\footnotetext{
* Correspondence: marietessie@gmail.com

'Department of Anaesthesia and Critical Care, Makerere University and

Mulago National Refferal Hospital, Kampala, Uganda

Full list of author information is available at the end of the article
}

In a bid to attain Millenium Development Goals 4 and 5 [4], attention is being focused on the very important area of childbirth. Analgesia for labour is widely utilized in high-income countries but this is not the case in Africa [5]. Issues in high-income countries are focused on the choice of methods and complications, while in developing countries the issue revolves around awareness, acceptability and availability of analgesia for labour [6].

Various studies have been conducted on the subject not only in low income countries [6-14], but also in high income countries [15] and they have shown various factors affect women's attitudes to pain relief in labour. These include knowledge of labour analgesia (found to be low in several studies $[6-8,10-12,14]$, upbringing and culture [7, 16], education level [6,11,12, 17], age, among others.

Currently, the method of analgesia available in the labour ward is continuous support, which is inconsistently offered, mainly by the understaffed midwives. There being 
little data and no protocols for pain relief in labour in our setting, the study sought to assess the participants' knowledge of pain relief during labour and their beliefs, values and attitudes toward labour analgesia.

\section{Methods}

Upon obtaining institutional and ethical approval from the Makerere University College of Health Sciences School of Medicine Research and Ethics Committee, we performed a cross-sectional descriptive study.

The study was conducted in Mulago National Referral Hospital, which is also the teaching hospital of Makerere University. It serves a variable population from all-over the country, and also handles referrals from neighbouring countries. It was carried out in the general antenatal clinic in the hospital.

The clinic runs 3 days every week. Over 1,000 mothers are seen on average monthly, of which 400-500 are attending their first antenatal visit. The first antenatal visit for most of the participants was during the first trimester, although a few of them attended their first antenatal clinic during the second or third trimesters.

Women were requested to complete the researcheradministered survey following informed consent. The mothers read the survey and study investigators were available to assist participants completing the survey and clarify any questions that arose. Verbal and written Luganda (the common local dialect) translation was provided to those whose first language was Luganda. The survey was conducted in the morning when study participants were still fresh.

The survey consisted of two sections. The first section examined demographics, (age, religion, education level, parity, occupation, residence and previous caesarean delivery). The second section consisted of 15 questions, and assessed knowledge and options of labour analgesia, sources of information and perceptions on labour analgesia. Among those with a previous experience of delivery, participants were to score their previous pain experience using the numeric rating score. On average, each survey took about $10 \mathrm{~min}$. These questions were developed from a focused discussion by the authors. Each question expressed only one idea (i.e., no questions contained "and") and no questions were phrased in a negative form. Answer types included choosing from a menu of choices, yes/no/neutral, or pains scores on a scale of 0 to 10 (not and).

\section{Statistical analysis}

Calculation of the sample size was based on the number of factors we wanted to analyze as possible predictors of the use of labour analgesia during labour. In order to evaluate up to 10 predictive factors in a multivariate model and ensure stability of the regression calculation, we estimated the requirement of 120 patients with the outcome measure per degree of freedom. Thus, a minimum of 1,200 patients would be required.

Descriptive statistics were used to summarize demographics and outcomes. We first conducted univariate analyses (Student -test, Wilcoxon-Mann-Whitney or Chisquared tests as appropriate) to analyze factors determined a priori to be potentially important. A factor found to have a statistically significant association with a patient having no knowledge of labour analgesia with univariate analysis was considered a potential predictive factor. Data were analyzed using Microsoft Excel and SPSS (Version 11).

STUDY PROFILE

2720 mothers attended antenatal care at Mulago National

referral hospital between 04/Mar/2013 to 24/May/2013

1427 excluded

- 35 mothers were below 18 years

- 1422 were attending their second, third or fourth antenatal visit

1298 mothers were eligible for study

5 mothers did not give informed consent

1293 mothers included in the study and Interviewed

Fig. 1 Study profile 


\section{Results}

A total of 1,293 pregnant women was recruited in this study out of 2,720 mothers who attended the antenatal clinic during the study period (Fig. 1). Of these, $66 \%$ were 30 years and below, $80 \%$ had at least one child and $55 \%$ had attained secondary education and above (Table 1).

Only 91 (7\%) of the women in this study had any knowledge of labour analgesia (Table 2).

Table 1 Demographics

\begin{tabular}{|c|c|c|}
\hline \multirow[t]{2}{*}{ Characteristic } & \multicolumn{2}{|c|}{$\begin{array}{l}\text { Distribution of study participants, } \\
\text { Total }=1,293\end{array}$} \\
\hline & Number & Percentage \\
\hline \multicolumn{3}{|c|}{ Age groups in years } \\
\hline 1. $18-30$ & 850 & 65.8 \\
\hline 2. $31-40$ & 429 & 33.2 \\
\hline 3. $>40$ & 12 & 0.9 \\
\hline 4. No response & 2 & 0.1 \\
\hline \multicolumn{3}{|l|}{ Religion } \\
\hline 1. Catholic & 405 & 31.3 \\
\hline 2. Anglican & 381 & 29.5 \\
\hline 3. Muslim & 328 & 25.4 \\
\hline 4. Others & 175 & 13.5 \\
\hline 5. No response & 4 & 0.3 \\
\hline \multicolumn{3}{|l|}{ Education Level } \\
\hline 1. No education & 29 & 2.2 \\
\hline 2. Primary & 546 & 42.2 \\
\hline 3. Secondary & 624 & 48.3 \\
\hline 4. Undergraduate & 81 & 6.3 \\
\hline 5. Post graduate & 8 & 0.6 \\
\hline 6. No response & 5 & 0.4 \\
\hline \multicolumn{3}{|l|}{ Occupation } \\
\hline 1. Unemployed & 554 & 42.8 \\
\hline 2. Small business & 597 & 46.2 \\
\hline 3. Professional & 93 & 7.2 \\
\hline 4. Informal & 49 & 3.8 \\
\hline \multicolumn{3}{|l|}{ Residence } \\
\hline 1. Rural & 122 & 9.4 \\
\hline 2. Urban & 1,165 & 90.1 \\
\hline 3. No response & 6 & 0.5 \\
\hline \multicolumn{3}{|l|}{ Parity } \\
\hline 1. Primiparous & 264 & 20.4 \\
\hline 2. Multiparous & 1,029 & 79.6 \\
\hline \multicolumn{3}{|l|}{ Previous C/S } \\
\hline 1. Yes & 503 & 38.9 \\
\hline 2. No & 788 & 60.9 \\
\hline 3. No response & 2 & 0.2 \\
\hline
\end{tabular}

Table 2 Knowledge of Labour Analgesia

\begin{tabular}{llll}
\hline & Number & Percentage & $95 \% \mathrm{Cl}$ \\
\hline Yes & 91 & 7.0 & $5.64-8.43$ \\
No & 1,202 & 93.0 & $91.57-94.36$ \\
\hline
\end{tabular}

Regarding attitudes and beliefs, $87.8 \%$ of the participants felt that labour should be pain-free, $10 \%$ that labour pain is natural and should be experienced. Of those with experience of previous labour, 686 (66.7 \%) described the pain as severe (Fig. 2). Participants who thought any doctor could give labour analgesia were 967 $(78.6 \%)$, and $3(0.2 \%)$ said an anaesthesia provider gives labour analgesia. All three were multiparous. A significant majority, 1,134 (87.7 \%) of the participants said they wanted to have labour analgesia for their next delivery (Table 3). However, even among those who wanted labour analgesia for the next delivery, there were some concerns, mainly that the baby may be affected (54.5\%), the method may not work (23.4\%), among others (Table 3).

Concerning those who did not want labour analgesia for their next delivery, $45 \%$ said they wanted to experience natural childbirth, $8 \%$ said it was against the will of God, $8 \%$ thought it would harm the baby, $5 \%$ said they would love their baby more, $1 \%$ said the pain was a form of birth control (Fig. 3).

Majority (47 \%) of those who knew about labour analgesia got the information from friends and family,26\% from the previous labour, $7 \%$ from the media and $1 \%$ from literature (Fig. 4). Among methods of analgesia known, 24 (26\%) women said local herbs ("others" in Fig. 5), 19 (21 \%) injection in the lower back (whether spinal or epidural), among others (Fig. 5). No mother mentioned "epidural" in particular, however. The study showed multiparity had a positive correlation (0.52 CI $0.32-0.85, p$-value 0.009 ) with acceptability of labour analgesia, while age and education did not affect acceptability ( $p$-values $>0.08$ ). Also, those who had history of Caesarean section were less likely to accept labour analgesia (1.88 CI $1.34-2.63$, $p$-value 0.001$)$.

Asked if any method of labour analgesia had been used in the previous delivery, 894 (87.9\%) of the participants reported that they did not get labour analgesia, although $79.2 \%$ of the multiparous participants had delivered in the national referral hospital (Table 3).

\section{Discussion}

This study found that very few mothers knew of labour analgesia. Despite their lack of prior knowledge, majority want to have labour analgesia for their next delivery. Of the multigravida mothers, many had delivered in a national referral hospital, however many said they did not have labour analgesia during their previous delivery. 


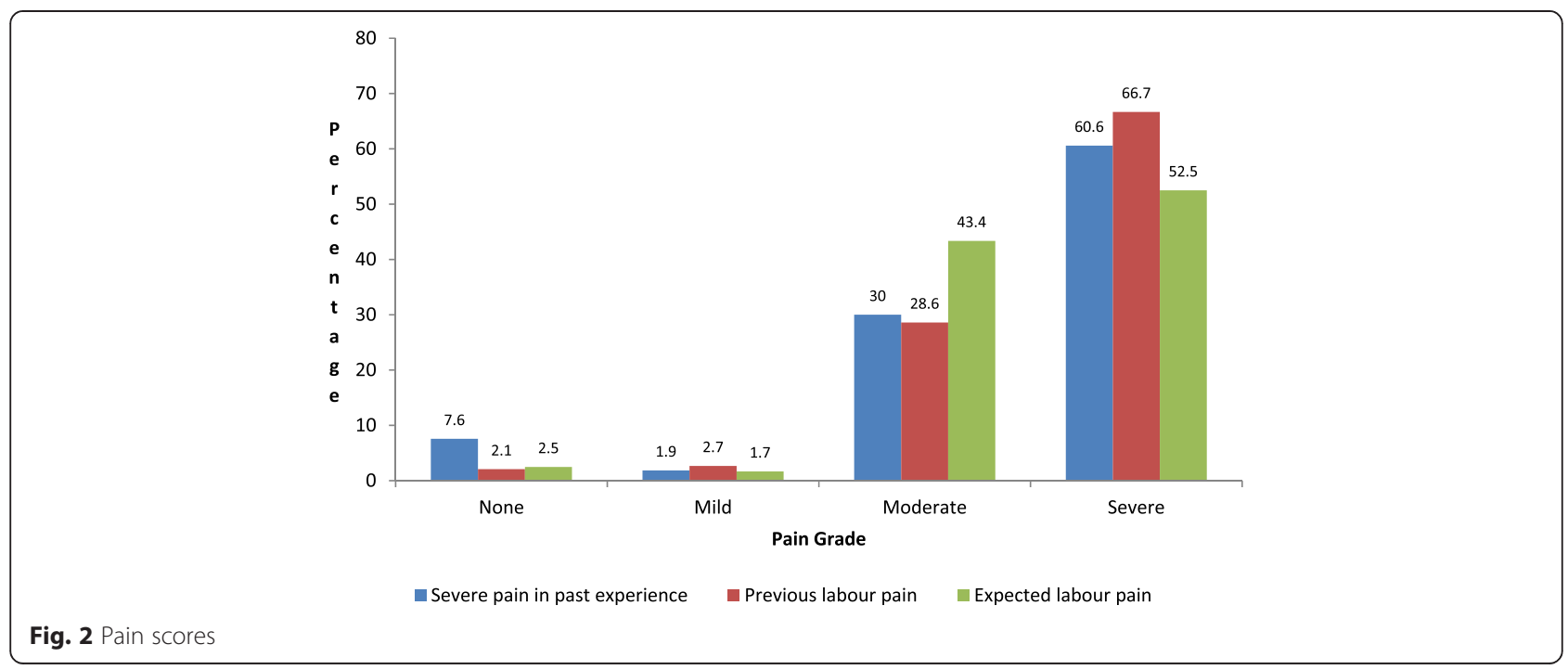

Among those who had knowledge of labour analgesia, the commonest source of information was friends and relatives. Few got information from the previous labour, even fewer from media and literature. While over $50 \%$ had attained at least secondary education, the number with primary level education and below is still significant.

Many of the multigravida mothers described the pain from their previous delivery as severe. It is therefore not surprising that majority of the mothers in the study (both prime gravida and multigravida) believed that labour should be pain-free. However, a few mothers did not want labour analgesia for their subsequent delivery

Table 3 Desire for labour analgesia, place of previous delivery, and concerns about labour analgesia

\begin{tabular}{lll}
\hline Variable & \multicolumn{2}{c}{ Distribution of participants } \\
\cline { 2 - 3 } & \multicolumn{1}{c}{ Number } & Percentage \\
\hline Do you want labour analgesia? (Total 1293) & 1,134 & 87.7 \\
1. Yes & 156 & 12.1 \\
2. No & 3 & 0.2 \\
3. No response & 181 & 17.6 \\
Place of previous baby delivery among the parous (Total 1029$)$ \\
1. Private health facility & 815 & 79.2 \\
2. National referral hospital & 33 & 3.2 \\
3. No response & & \\
Concerns about pain relief & 391 & 54.5 \\
1. Baby may be affected & 45 & 6.3 \\
2. Contractions may be weakened & 68 & 9.5 \\
3. Inability to push or use lower part & 5 & 0.7 \\
4. May lead to C/S or instrument use & 5 & 23.4 \\
5. Method may not work & 168 & 5.7 \\
6. Other & 41 & \\
\hline
\end{tabular}

and the commonest reason was to experience natural childbirth; others said it was against the will of God.

From these results, there is a clear need for labour analgesia by the pregnant mothers, however for various reasons, it is not provided. One of the contributing factors is the fact that there is no established labour analgesia service, even in the national referral hospital. Given the commonest source of information, the mothers are not getting this information from the obstetricians during their antenatal visits. A very small percentage of mothers cited literature as a source of information because the literature is not readily available. Judging from the various beliefs and views expressed by the mothers regarding labour analgesia, culture and religion play a role in decisions made. The results also showed that multigravida mothers are more likely to accept labour analgesia.

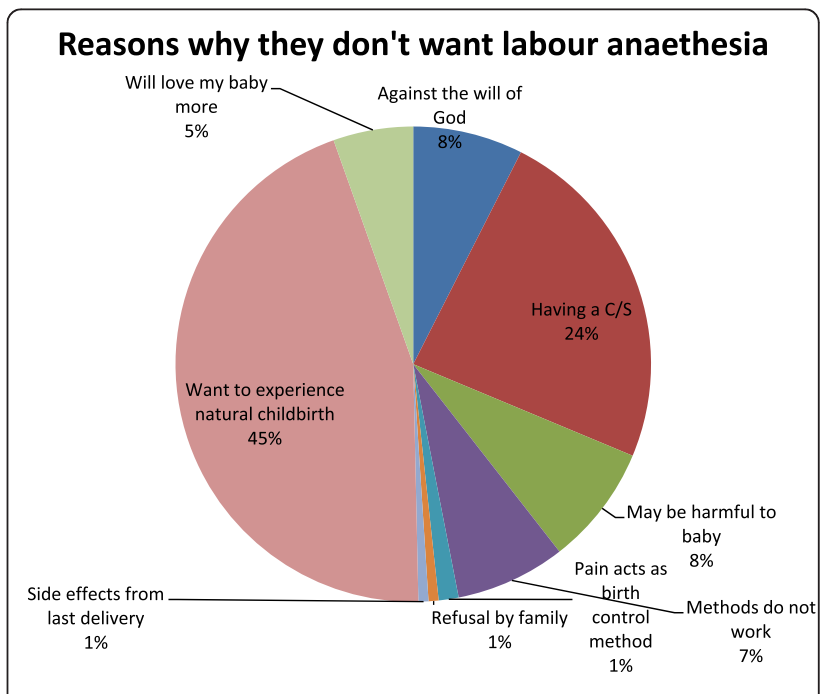

Fig. 3 Among those who do not want labour analgesia 


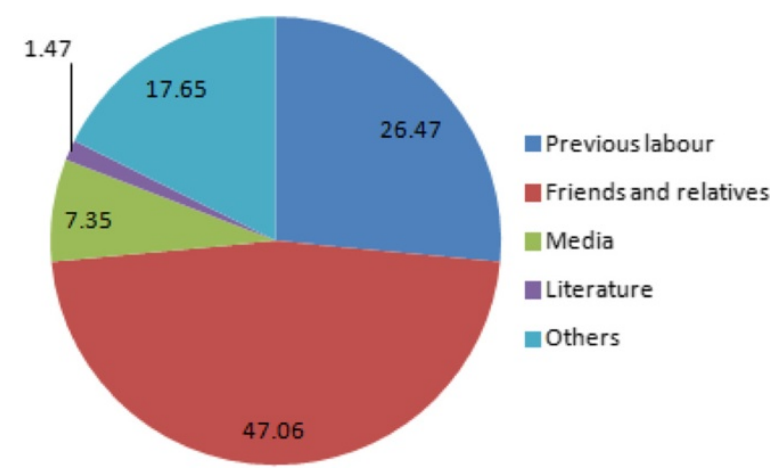

Fig. 4 Source of Information about Labour Analgesia

Several studies have been done on the subject in other developing countries. The study by Naithani et al. is comparable to this study $(9.5 \%$ knowledge of labour analgesia) [11]. Many other studies in LMICs also showed low level of knowledge $[6-8,10]$ compared to the developed world [18]. An audit by Taneja, Nath and Dua (2004) in India showed that majority of the obstetricians were not taught labour analgesia during their training programme and their practical exposure to it was very limited [19]. This may be the case in this study as well. Regarding acceptability of labour analgesia, this study was comparable to that by Audu et al. [7]. However, acceptance was not high in the studies by Naithani et al. [11] and Olayemi et al. [6], the commonest reason being to experience natural childbirth, similar to this study. In the study by Toledo et al., desire to experience unmedicated ("natural") childbirth was one of the major reasons for avoiding neuraxial analgesia [15]. Also similar to this study were the concerns about effects on the baby and the method leading to caesarean delivery. While this study showed a positive correlation between parity and acceptability of labour analgesia, Okeke et al. [12] found no association. Olayemi et al. [6] found that education had a positive correlation and age a negative correlation. In this study, age and education did not affect acceptance. No other studies were found comparing previous Caesarean section history and acceptance of labour analgesia. Our study showed a negative correlation. Some of the women who had Caesarean sections had long periods of labour pain before an emergency $\mathrm{C}$-section was performed, and therefore would not want to go through labour again.

Our study limitations included the fact that we excluded mothers below 18 years and yet these contribute significantly to the prime gravida population in the hospital, and the country as a whole. It would have been worthwhile to investigate their attitudes and views concerning labour analgesia. Additionally, study was done in the antenatal period. It would probably be more informative if it was extended to and after the time of labour.

Having been conducted in the antenatal period, the study made no provision for analgesia at the time of labour. This is partly because it is not an established service in the hospital, hence the need for studies such as this one to form a baseline for establishing a labour analgesia service in the hospital. The standard of care is however offered to every parturient.

\section{Conclusion}

From this study, it is very clear that there is a wide gap between desire for labour analgesia and its provision. Obstetricians and anaesthesia providers have a great

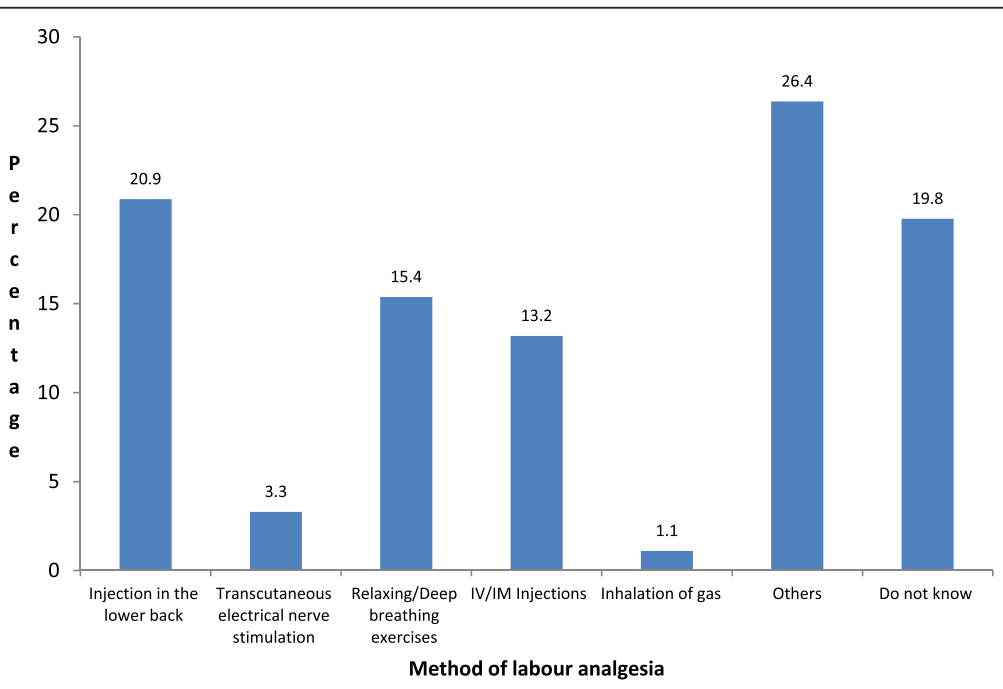

Fig. 5 Known methods among those who had knowledge of labour analgesia 
role to play in educating the mothers, and possibly their colleagues, on the various methods of labour analgesia before the service can be set up. Labour analgesia is a standard of care in obstetrics and so should be provided in the national referral hospital.

In conclusion, very few pregnant mothers know about labour analgesia but majority would love it.

\section{Abbreviations}

ACOG: American College of Obstetricians and Gynecologists; ASA: American Society of Anesthesiologists; LMICs: Low and Middle Income Countries.

\section{Competing interests}

The authors declare that they have no competing interests.

\section{Authors' contributions}

MN contributed to study design, conduct of the study, acquisition of data, data analysis, and manuscript preparation. The name has been re-arranged to Andrew Kintu. Because of the similarity of initials with Arthur Kwizera, we shall use AK(1) for Andrew Kintu and AK(2) for Arthur Kwizera. and AW contributed to study design and manuscript preparation. MM and AK(2) contributed to study design, conduct of the study, data analysis and manuscript. All authors read and approved the final manuscript.

\section{Acknowledgements}

The authors would like to acknowledge Dr. J. V. B Tindimwebwa and Ass. Prof. Gerald Dubowitz for their assistance in manuscript development, and the Association of Anaesthesiologists of Great Britain and Ireland (AAGBI) and Global Partners in Anesthesia and Surgery (GPAS) for their financial support.

\section{Author details}

${ }^{1}$ Department of Anaesthesia and Critical Care, Makerere University and Mulago National Refferal Hospital, Kampala, Uganda. ${ }^{2}$ Department of Obstetrics and Gynaecology, Makerere University College of Health Sciences, Kampala, Uganda.

Received: 14 October 2014 Accepted: 24 June 2015

Published online: 07 July 2015

\section{References}

1. Practice Guidelines for Obstetric Anaesthesia. An updated report by the American Society of anesthesiologists task force on obstetric anesthesia. Anesthesiology. 2007;106:843-63.

2. ACOG Practice Bulletin No. 36. Obstetric Analgesia and Anesthesia. 2002

3. ACOG Committee Opinion \#295. Pain relief during labor. Obstet Gynecol. 2004;104:213.

4. United Nations. The Millenium Development Goals Report. United Nations Department of Economic and Social Affairs - June 2010.

5. Kuti O, Faponle AF, Adeyemi AB, Owolabi AT. Pain Relief in labour: A randomized controlled trial comparing pentazocine with Tramadol. NJOG. 2008:3:14-8

6. Olayemi O, Aimakhu CO, Udoh ES. Attitudes of patients to obstetric analgesia at the University College Hospital, Ibadan, Nigeria. J Obstet Gynecol. 2003;23:38-40.

7. Audu B, Yahaya U, Bukari M, El-Nafaty A, Abdullahi H, Kyari O. Desire for pain relief in labour in Northeastern Nigeria. J Publ Health Epidemiol. 2009;1:053-7.

8. Barakzai A, Haider G, Yousuf F, Haider A, Muhammad N. Awareness of women regarding analgesia during labour. J Ayub Med Coll Abbottabad. 2010;22

9. Mugambe JM, Nel M, Hiemstra LA, Steinberg WJ. Knowledge of and attitude towards pain relief during labour of women attending the antenatal clinic of Cecilia Makiwane Hospital South Africa. SA Fam Pract. 2007:49:16.

10. Mung'ayi V, Nekyon D, Karuga R. Knowledge, attitude and use of labour pain relief methods among women attending antenatal clinic in Nairobi. East Afr Med J. 2008;85:9.

11. Naithani U, Bharwal P, Chauhan SS, Kumar D, Gupta S, Kirti. Knowledge, attitude and acceptance of antenatal women toward labor analgesia and caesarean section in a medical college hospital in India. J Obstetric Anaesth Crit Care. 2011;1:13-20.

12. Okeke Cl, Merah NA, Cole SU, Osibogun A. Knowledge and perception of obstetric analgesia among prospective parturients at the Lagos University Teaching Hospital. Niger Postgrad Med J. 2005;12:258-61.

13. Olayemi O, Adeniji RA, Udoh ES, Akinyemi OA, Aimakhu CO, Shoretire KA. Determinants of pain perception in labour among parturients at the University College Hospital Ibadan. J Obstet Gynaecol. 2005;25:128-30.

14. Shidhaye RV, Galande M, Bangal VB, Smita J, Shidhaye UR. Awareness and attitude towards labour analgesia of Indian pregnant women. Anaesth Pain \& Intensive Care. 2012;16:131-6.

15. Toledo P, Sun J, Peralta F, Grobman WA, Wong CA, Hasnain-Wynia R. A qualitative analysis of parturients' perspectives on neuraxial labor analgesia. Int J Obstet Anesth. 2013;22:119-23.

16. Faponle AF, Kuti O. Perception of labour pain by pregnant women in Southwestern Nigeria. Trop J Obstet Gynaecol. 2004;21:153-5.

17. Ogboli-Nwasor E, Adaji SE, Bature SB, Shittu OS. Pain relief in labor: a survey of awareness, attitude, and practice of health care providers in Zaria Nigeria. J Pain Res. 2011:4:227-32.

18. Biswas G, Hariharan V. A survey of antenatal women on their knowledge of pain relief methods in labour. Royal Coll Anaesth. Bulletin. 2002;11:530-1.

19. Taneja B, Nath K, Dua CK. Clinical audit on the existing attitudes and knowledge of obstetricians regarding labour analgesia. Indian J Anaesth. 2004;48:185-8.

\section{Submit your next manuscript to BioMed Central and take full advantage of:}

- Convenient online submission

- Thorough peer review

- No space constraints or color figure charges

- Immediate publication on acceptance

- Inclusion in PubMed, CAS, Scopus and Google Scholar

- Research which is freely available for redistribution 